\title{
Acessibilidade informacional para pessoas com deficiência visual em uma biblioteca universitária
}

\author{
Informative accessibility for people with visual disabilities in a university library
}

\author{
Maria José Rodrigues de Castro \\ Mestre em Biblioteconomia pela Universidade Federal do Cariri - UFCA, Brasil. \\ E-mail: mayse.castro@gmail.com \\ Marcus Vinicius de Oliveira Brasil \\ Pós-Doutor em Administração e Controladoria pela Universidade Federal do Ceará - UFC, Brasil. \\ Professor Adjunto da Universidade Federal do Cariri - UFCA, Brasil. \\ https://orcid.org/0000-0001-6525-9257 \\ E-mail: marcus.brasil@ufca.edu.br
}

\section{Resumo}

Procura verificar se há acessibilidade informacional para pessoas com deficiência visual em uma biblioteca universitária, levando-se em consideração tipos de acessibilidade como a arquitetônica, comunicacional e instrumental. A pesquisa é um estudo de caso, complementado por revisão bibliográfica. Como instrumento de levantamento de dados, utilizou-se de checklist, que contempla itens referentes às normas e legislações inerentes à acessibilidade para pessoas com deficiência. É uma pesquisa de natureza aplicada, de caráter exploratório e descritivo. A abordagem dos dados é de natureza qualitativa. Com o estudo, a discussão sobre o tema chama atenção para práticas mais efetivas de acessibilidade informacional para pessoas com deficiência visual em bibliotecas universitárias e aspectos intrínsecos à função fim de disseminar a informação para um público específico. Conclui-se que a acessibilidade informacional na biblioteca pesquisada se dá de forma parcial, visto que o acesso efetivo à informação no espaço físico apresenta ausência de requisitos elencados nas normas e recomendações de acessibilidade, embora haja instrumentos adequados e convenientes para prestação de serviços e produtos informacionais adaptados para este público.

Palavras-chave: Acessibilidade informacional. Pessoa com deficiência visual. Biblioteca universitária.

\begin{abstract}
It seeks to verify if there is informational accessibility for people with visual impairments in a university library, taking into account types of accessibility such as architectural, communicational and instrumental. The research is a case study, complemented by a bibliographic review. As a data collection instrument, a checklist was used, which includes items related to the rules and legislation inherent to accessibility for people with disabilities. It is an applied research, exploratory and descriptive. The data approach is qualitative in nature. With the study, the discussion on the theme calls attention to more effective practices of informational accessibility for people with visual impairments in university libraries and aspects intrinsic to the function in order to disseminate information to a specific audience. It is concluded that the informational accessibility in the researched library occurs in a partial way, since the effective access to information in the physical space presents the absence of requirements listed in the accessibility standards and recommendations, although there are adequate and convenient instruments to provide services and products information adapted for this audience.
\end{abstract}

Keywords: Informational accessibility. Visually impaired person. University library. 


\section{Introdução}

Os milhares de estudantes que ingressam anualmente nas universidades brasileiras, em específico, nas públicas federais, além de possuírem características ímpares de personalidade e a diversidade de desejos de seguirem profissões distintas, podem possuir dificuldades físicosensoriais, características que requerem ambientes acessíveis que minimizem as dificuldades impostas pela ausência de um dos sentidos ou dificuldades causadas por limitações temporárias ou permanentes impedindo que essas pessoas possam desenvolver suas atividades com igualdade de condições e concluírem seus cursos com êxito, caso não haja um ambiente inclusivo e com acessibilidade.

Com isso, é conveniente que todos os setores da universidade estejam cientes de seus papéis e, principalmente os que atendem ao público com funções que interferem diretamente no desenvolvimento de suas atividades enquanto discentes. Nesta perspectiva, tem-se como setor primordial em uma Instituição de Ensino Superior (IES), a biblioteca universitária com a função de dar suporte informacional aos estudantes, de acordo com as matrizes curriculares dos cursos ofertados pela IES, além de observar a necessidade específica de cada usuário quanto à forma de acesso a essas informações, indo ao encontro do estabelecido nas legislações e normas de acessibilidade para pessoas com deficiência e, consequentemente, da satisfação dos usuários da biblioteca.

Nesse sentido, fez-se um recorte para uma biblioteca universitária em nível federal, a fim de explorar como se caracteriza a prestação de seus produtos e serviços em seu espaço físico, enfim, se a acessibilidade informacional está presente, levando em consideração outros tipos de acessibilidade, como a arquitetônica e comunicacional para pessoas com deficiência visual. Entender se de fato, a biblioteca pesquisada está apta a receber e atender de forma satisfatória este público.

A relevância desta discussão está não só na existência de legislações e normas nacionais e interacionais que regulamentam a prática das instituições no que lhes compete em dar condições justas e igualitárias de acesso ao lazer, educação, trabalho, cultura, enfim, à informação, no caso deste estudo, mas no grande número de pessoas que se declararam com deficiência visual no último Censo Populacional no Brasil em 2010, realizado pelo Instituto Brasileiro de Geografia e Estatística (IBGE), em que mesmo com uma nova releitura dos dados estatísticos publicado através de nota técnica emitida em meados de 2018 , onde reduziu de 
45.606.048, das 190.755.048 pessoas recenseadas, cerca de $23,9 \%$ para $12.748 .663,6,7 \%$, a população que respondeu possuir ter alguma deficiência, ainda assim, o maior percentual em relação aos tipos, é de pessoas com deficiência visual, com cerca de 3,4\%, conforme verificase no gráfico1 a seguir (IBGE, 2018):

Gráfico 1 - Proporção de pessoas com deficiência, com e sem aplicação da linha de corte do WG, por tipo de deficiência - Brasil 2010

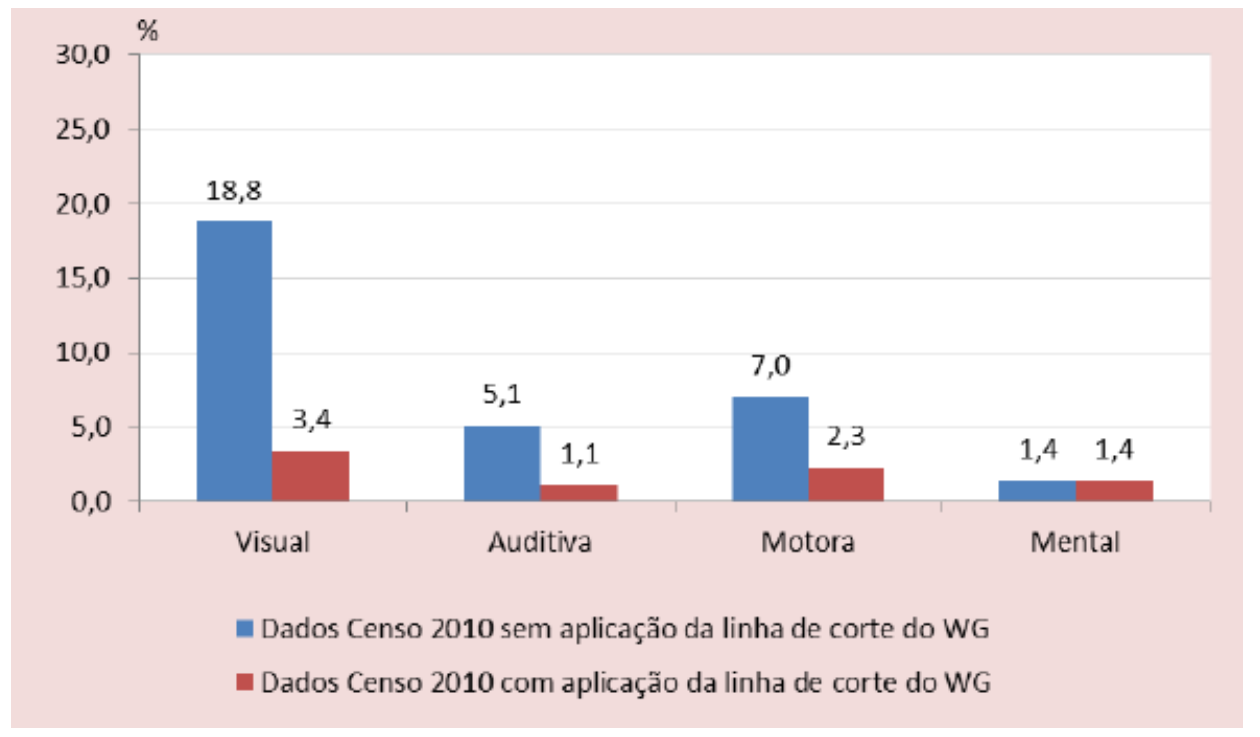

Fonte: IBGE, 2018

Pode-se verificar no gráfico 1, que antes da releitura, o percentual de pessoas com deficiência visual era de 18,8\% e após o IBGE adotar a correção, baseada na linha de corte do Grupo de Washington, diminui para 3,4\%, onde para identificar a população com deficiência visual severa, considerou apenas afirmativas como "não conseguem de modo algum" ou "possuem grande dificuldade" para a pergunta "tem dificuldade permanente de enxergar?", mesmo utilizando aparelhos para correção da visão, como óculos, lentes de contato. Antes, também era considerado nos dados quem afirmou ter "alguma dificuldade" nas mesmas condições já mencionadas (IBGE, 2018, p. 4).

Dados como esses são norteadores e impulsionadores de esforços para elaboração e implementação de políticas públicas e programas governamentais e institucionais, a fim de reduzir as barreiras e distâncias entre os que enxergam e as pessoas com deficiência visual, que necessitam encontrar nos diversos ambientes e segmentos da sociedade, a exemplo, as bibliotecas universitárias, alternativas que eliminem obstáculos que dependem do sentido da visão, como a leitura de um livro impresso à tinta, por exemplo. 
Lembrando que não se deve pensar somente no produto final, o livro, mas na possibilidade de existir outros obstáculos, quando as edificações das bibliotecas localizadas geralmente dentro de campus universitários, organizada por seções, como acervo, balcão de referência (atendimento ao usuário), salas e salão de leitura coletiva, cabines de estudos individuais, serviço de processamento técnico, entre outros, não estão de acordo com as normas que determinam que espaços públicos como estes sejam acessíveis, levando em consideração o desenho universal, ou seja, que possa ser pensado de forma que todos, independentemente de suas características físico-sensoriais, possam utilizar.

Nesse contexto, o objetivo geral deste estudo foi investigar a acessibilidade informacional em uma biblioteca universitária, por via dos aspectos arquitetônicos, comunicacional e instrumental. Para se chegar ao objetivo geral, adaptou-se, o checklist de Nicoletti (2010), instrumento de coleta de dados proposto para avaliação de acessibilidade em bibliotecas, baseado em normas sobre acessibilidade em espaços físicos e literatura da área de Biblioteconomia para verificação da acessibilidade informacional para pessoas com deficiência visual, assim como identificar instrumentos e tecnologias assistivas utilizados na prestação de produtos e serviços para este público na Biblioteca Comunitária Jornalista Carlos Castelo Branco (BCCB) como estudo de caso.

\section{Revisão de literatura}

A acessibilidade é um termo que pode estar ligado a outros para especificá-lo quanto a caracterizar se determinado aspecto está dentro das possibilidades de ser acessado e utilizado de forma autônoma, segura e com conforto, conforme expresso no seu conceito inserido em dispositivos normativos e legais, como a ABNT NBR 9050/2020 e o Estatuto da Pessoa com Deficiência, através da Lei n. 13.146/2015, onde diz que acessibilidade é:

[...] possibilidade e condição de alcance para utilização, com segurança e autonomia, de espaços, mobiliários, equipamentos urbanos, edificações, transportes, informação e comunicação, inclusive seus sistemas e tecnologias, bem como de outros serviços e instalações abertos ao público, de uso público ou privado, de uso coletivo, tanto na zona urbana como na rural, por pessoa com deficiência ou mobilidade reduzida. (BRASIL, 2015, p. 2).

Conforme conceito de acessibilidade mencionado acima no Estatuto da Pessoa com Deficiência, acessibilidade é propiciar que pessoas com deficiência possam utilizar com independência e segurança todos os espaços e sistemas, tanto comunicacionais, quanto 
informacionais, inclusive as tecnologias e aparelhamento utilizados para tal, seja no meio urbano ou rural.

Para Torres, Manzonni e Alves (2002, p. 83) "a acessibilidade é conceito que envolve tanto espaço físico, o espaço em que vivemos, como o espaço digital”.

Há autores que falam sobre a acessibilidade em bibliotecas e que focam seus trabalhos em um tipo específico de deficiência na maioria da literatura encontrada sobre o assunto. Os trabalhos que tratam as questões de acessibilidade para pessoas com deficiência visual, citamse D’Abreu et al. (2008), Ferreira e Cianconi (2011), Passos e Vieira (2008), Pupo, Carvalho e Oliveira (2008), Souza e Tabosa (2014), Vigentim (2014), Malheiros (2019), entre outros autores.

Observa-se que apesar de não estar explícito o termo acessibilidade informacional, a temática é semelhante e recai na mesma finalidade, que é a de investigar a acessibilidade em bibliotecas, e, portanto, a informação, o conhecimento para pessoas com limitação visual.

Acredita-se que os autores abordam mais a acessibilidade às pessoas com deficiência visual, por vários motivos, dentre eles as barreiras arquitetônicas, presentes em boa parte dos edifícios públicos e que constam como desafios não só para pessoas com deficiência visual, como também para os físicos, pessoas com mobilidade reduzida permanente ou temporária (idoso, gestante, lactante, pessoa com criança de colo e obeso).

Em se tratando de espaços como a biblioteca universitária, o termo mais utilizado é acessibilidade informacional, conforme vem se denominando na literatura em alguns trabalhos, principalmente na literatura cinzenta, conforme menciona Fernandes (2018), ao fazer uma pesquisa sobre a expressão "acessibilidade informacional" nas principais bases de dados que indexam trabalhos sobre Ciência da informação, datados entre 2011 e 2017, observou a inserção do termo associado a determinados tipos de deficiência ou aspectos e muito pouco, relacionado ao público como um todo, sugerindo um conceito diante da escassez percebida em sua pesquisa sobre acessibilidade informacional, onde coloca que esta possui:

\footnotetext{
característica relativa à diminuição e/ou remoção das barreiras no processo informacional, visando que as pessoas possam alcançar a satisfação de suas necessidades informacionais através de uma experiência positiva e com menor esforço necessário, obtendo resultados eficazes e condizentes com sua condição, seja ela qual for (FERNANDES, 2018, p. 43).
}

A autora ainda sugere a inserção do termo "acessibilidade informacional" como mais uma dimensão na classificação de acessibilidade de Sassaki (2009), até então, classificadas em 
seis: acessibilidade arquitetônica, comunicacional, atitudinal, instrumental, metodológica, programática e, em 2019, o autor incluiu a sétima dimensão, como indica o título da publicação "As sete dimensões da acessibilidade", classificando-a como natural, que trata de barreias e obstáculos naturais ou da natureza.

Scott Júnior (2011) infere que essas dimensões da acessibilidade são exemplificativas e não taxativas e de acordo com a realidade de um determinado contexto acadêmico universitário, medidas podem ser elaboradas e efetivadas para possibilitar a igualdade de oportunidades para as pessoas com deficiência. No entanto, a classificação mencionada por Sassaki (2009) serve de paradigma para nortear onde se deve chegar para uma acessibilidade para todos.

Outro conceito de acessibilidade informacional encontrado na literatura é de Santos e Araújo (2015) em que diz que a acessibilidade informacional é a dimensão que permite circular livremente e ter acesso às fontes e aos materiais de informação de forma confiável e com autonomia com tecnologias assistivas auxiliando na construção de recursos informacionais de busca, recuperação e uso da informação sem nenhuma interferência.

Concorda-se que a acessibilidade informacional abranja todos os aspectos que direcione ao acesso à informação onde ela estiver, livre de qualquer barreira que impeça o usuário de explorá-la.

Sabe-se que para oferecer produtos e serviços acessíveis em bibliotecas universitárias, é necessário resolver diversas questões estruturais, esforços direcionados para aquisição de recursos financeiros para concretização das políticas públicas e programas voltados para essas pessoas. Capacitação de pessoal e interesse dos gestores em direcionar mais esforços para eliminar as barreiras da acessibilidade.

Com o aperfeiçoamento e as várias discussões em torno de áreas de conhecimento, como Ciência da Computação, Arquitetura e Urbanismo, Ciência da Informação, Engenharias, Educação, Ciências Políticas, Linguística, Psicologia, Serviço Social, Comunicação, Direito, enfim, áreas de conhecimentos variados e suas ramificações que juntas, de forma direta ou indireta, dentro de suas perspectivas, de forma involuntária, contribuem cooperativamente para avanços no sentido de diminuir barreiras que impeçam o acesso e a transmissão de informação, conhecimento. 


\section{Metodologia aplicada}

Com o intuito de investigar a acessibilidade informacional para pessoas com deficiência visual na BCCB da Universidade Federal do Piauí (UFPI), principalmente para os discentes, nos casos em que houver usuários reais e potenciais, onde a biblioteca está localizada, através dos aspectos arquitetônico, comunicacional e informacional, fez-se o cotejo com as normas e legislações vigentes que tratam sobre o assunto, utilizando-se de checklist.

A BCCB, como sendo a maior do sistema em espaço físico e com um número de usuários superior às demais bibliotecas por se localizar na capital piauiense, Teresina, constituise em uma amostra por acessibilidade ou conveniência que segundo Gil (2010, p. 94) "Constitui o menos rigoroso de todos os tipos de amostragem. Por isso, é destituída de qualquer rigor estatístico. O pesquisador seleciona os elementos a que tem acesso [...]". Sendo assim, a pesquisa é de cunho não-probabilístico.

Do ponto de vista dos objetivos, a pesquisa tem caráter exploratório e descritiva e se utilizou da revisão de literatura, com auxílio documental e estudo de caso.

Segundo Gil (2010), a pesquisa exploratória tem como propósito proporcionar maior familiaridade com o problema, com vistas a torná-lo mais explícito ou a construir mais hipóteses. Seu planejamento é propício a ser flexível, pois considera aspectos relativos ao fenômeno estudado. Envolve levantamento bibliográfico, análise de exemplos com o problema estudado. Tanto estudo de caso, quanto as pesquisas bibliográficas costumam fazer parte da pesquisa exploratória. Para Yin (2005, p. 19), perguntas "como" e "por que" são utilizadas em estudos de caso e [...] "quando o foco se encontra em fenômenos contemporâneos inseridos em algum contexto da vida real".

Como afirma Yin (2005), no caso em curso, é necessário aplicar o protocolo ao estudo de caso incorporado, pois a BCCB, assim como outras bibliotecas possuem suas especificidades relacionada a vários aspectos, desde a tipologia a questões regionais, como a localização, aspectos econômicos, tempo de existência, por exemplo.

Nesta fase, seguir-se-á o checklist de observação in loco, sobre Acessibilidade para Bibliotecas e Centros de Documentação, produto do trabalho de Nicoletti (2010) e recomendado pela Federação Brasileira de Associações de Bibliotecários, Cientistas da 
Informação e Instituições (FEBAB), adaptado ao escopo deste trabalho, ou seja, à acessibilidade informacional para as pessoas com deficiência visual.

Quanto à finalidade da pesquisa trata-se de uma pesquisa aplicada, dessa forma, conforme Gil (2010), visa gerar conhecimentos para aplicação prática, dirigidos à solução de problemas específicos, fazendo-se uso do questionário semiestruturado como um dos instrumentos de coleta de dados. Para Gil (2011, p. 121):

\footnotetext{
O questionário é uma técnica de investigação composta por um conjunto de questões que são submetidas a pessoas com o propósito de obter informações sobre conhecimentos [...]. Apresenta uma série de vantagens: a) possibilita atingir grande número de pessoas, mesmo que estejam dispersas numa área geográfica muito extensa; b) implica menores gastos com pessoal, posto que não exige o treinamento dos pesquisadores.
}

A aplicação do questionário visou identificar instrumentos e as tecnologias assistivas utilizadas nos produtos e serviços oferecidos pela BCCB em relação à acessibilidade informacional para o usuário com deficiência visual e implícito a este, a acessibilidade comunicacional e instrumental, parte do objetivo geral da pesquisa.

Abordagem dos dados é de natureza qualitativa, e, após a aplicação da pesquisa, fez-se uso da análise de conteúdo, que é a descrição das informações contidas nas mensagens (BARDIN, 1977), tanto da literatura, quanto das resultantes das respostas do checklist in loco através de uma visita técnica e do questionário complementar com informações acerca do funcionamento institucional da biblioteca. Importante frisar que o presente estudo foi aprovado no comitê de ética.

\section{Contexto e resultados da pesquisa}

Em agosto de 1995, inaugurou-se a BCCB, subordinada à Reitoria da UFPI e responsável por coordenar o SIBi-UFPI, instituído pela Resolução do Conselho Universitário $n^{0} 26 / 93$, que tem como função promover o acesso à informação e dar suporte às atividades de pesquisa e extensão no âmbito da UFPI, contribuindo para o desenvolvimento cultural, econômico e social do Estado do Piauí (UFPI, 2016).

O SIBI-UFPI é constituído pela BCCB, que concentra características de biblioteca universitária e comunitária ao mesmo tempo; 8 (oito) setoriais universitárias, sendo 5 (cinco) distribuídas pelos Centros na sede do Campus Universitário Ministro Petrônio Portella em Teresina e 3 (três) localizadas nos campis fora de sede, Amilcar Ferreria Sobral (Floriano), 
Senador Helvídio Nunes de Barros (Picos), Prof. ${ }^{a}$ Cinobelina Elvas (Bom Jesus). O Sistema atende usuários (docentes e discentes de graduações, pós-graduação presenciais e à distância e servidores técnicos administrativos), além dos vários polos do Centro de Educação Aberta e à Distância (CEAD) e o Plano Nacional de Formação de Professores da Educação Básica (PARFOR) sediados em outros municípios do Estado do Piauí.

A BCCB disponibiliza à comunidade acadêmica interna e servidores da UFPI, acervo bibliográfico em seus diversos suportes, impressos, multimeios, on-line acesso ao Portal de Periódicos da Capes e às inúmeras bases de dados disponíveis de forma gratuita para pesquisadores que possuem vínculo com a UFPI.

Treinamento de usuários é um serviço fim promovido aos usuários do sistema a fim de capacitá-los para uso eficiente do sistema de pesquisa ao acervo, normas quanto à utilização do acervo (empréstimo, renovação, reserva); utilização dos espaços das bibliotecas, serviços e produtos, sanções quando do atraso na devolução ou perda de publicações bibliográficas.

Além da orientação quanto às normas relacionadas à informação e documentação da ABNT; levantamento bibliográfico; Repositório Institucional da UFPI (RI/UFPI); visita guiada aos espaços das bibliotecas; ficha catalográfica ou catalogação na fonte, orientações quanto ao depósito de trabalhos de conclusão de curso; relatórios técnicos e estatísticos.

\subsection{Análise dos dados}

Para verificar a acessibilidade informacional para os usuários com deficiência visual na $\mathrm{BCCB}$, propôs-se observar para compará-los junto às normas e legislações, aspectos arquitetônicos, o entorno da edificação (transporte público, pontos de ônibus, estacionamento, calçadas, guias e faixas de pedestres) e espaços internos da biblioteca (desníveis, rampas, escadas, corrimãos, degraus isolados, pisos, corredores, iluminação, sanitários e tecnologias assistivas), bem como aspectos comunicacionais (sinalizações) e informacionais. 


\subsubsection{Acessibilidade arquitetônica e entorno da BCCB}

Na cidade de Teresina, localização do campus Petrônio Portela da UFPI, em que está situada a BCCB, o transporte coletivo público dá-se em sua maioria por meio de ônibus. Segundo a NBR ABNT 14022:2011-Acessibilidade em veículos de características urbanas para transporte coletivo, os coletivos acessíveis devem estar identificados com o Símbolo Internacional de Acesso (SIA), tanto na parte frontal, quanto na lateral e traseira do veículo, bem como a identificação do número, destino da linha, elementos encontrados nos coletivos das linhas que circulam no campus, indicando uma condução acessível.

Embora não se tenha encontrado no momento desta pesquisa (julho a setembro de 2020) pisos táteis nas calçadas, pontos de ônibus com sistemas sonoros com indicação de aproximação e horários disponíveis dos coletivos, há aplicativos que instalados em dispositivos móveis com acesso à internet e leitores com sintetizadores de voz podem fazer localização de linhas de ônibus em tempo real, facilitando o acompanhamento pelos usuários com deficiência visual que utilizam estes coletivos.

O acesso à biblioteca é parcialmente livre de obstáculos possuindo guia rebaixada com alargamento das calçadas. Há duas faixas de pedestres próximas à entrada da biblioteca e na oportunidade, foi encontrado piso tátil de alerta em apenas uma das faixas, faltando o piso tátil direcional em ambas, necessitando adequação quanto à ABNT NBR 9050 (2020) que recomenda ter pelo menos uma referência, sendo pisos táteis de alerta e direcional de no mínimo, $40 \mathrm{~cm}$ de largura na extensão da faixa ou sinalização sonora, itens ausentes nas faixas, o que as tornam parcialmente acessíveis.

Há no trajeto do ponto de ônibus para a entrada da BCCB, rotas acessíveis, como linha guia, que substitui o piso direcional tátil, desde que seja mantida cor contrastante da área adjacente como referência diferenciando-a, conforme consta na definição de sinalização direcional da NBR 9050 (2020, p. 33) "sinalização utilizada para indicar direção de um percurso ou a distribuição de elementos de um espaço e de uma edificação. [...] Na forma tátil, utiliza recurso como linha guia ou piso tátil”. A linha guia citada na visão de Ronchetti (2020) pode ser piso liso contínuo de cimento na cor clara contrastando com a vegetação verde, ou seja, com referência visual e tátil. Sendo assim, o piso tátil poderá ser uma das opções para direcionar as pessoas com limitação visual, mas não a única.

InCID: R. Ci. Inf. e Doc., Ribeirão Preto, v. 12, n. 1, p. 104-124, mar./ago. 2021. 
O estacionamento da BCCB é amplo, contemplando vagas reservadas para pessoas com deficiência, apesar da pintura do SIA na sinalização horizontal estar meio desgastada, há a área reservada na lateral da vaga com piso demarcado regular e estável.

Dessa forma, o entorno da biblioteca pesquisada é parcialmente favorável à circulação de pessoas com deficiência visual.

\subsubsection{Espaços internos}

A edificação da $\mathrm{BCCB}$ é do tipo vertical com dois pavimentos. $\mathrm{O}$ acesso à entrada principal dá-se por meio de uma porta em vidro fumê, contrastando com a área adjacente (paredes e batente) apenas com faixas na cor amarela não contínua. Observou-se que o destaque das listras em amarela e preto na entrada da biblioteca está meio apagado, sendo a cor da porta e sua moldura igual ao vidro das paredes adjacentes, dificultando, assim, sua identificação por pessoas com baixa visão. Uma das recomendações da ABNT 9050 (2020, p. 140) diz que: "Se os batentes em volta das portas tiverem contraste visual com as paredes, a oportunidade de identificar a presença da porta está disponível mesmo quando a porta estiver aberta”.

Ainda sobre a entrada da biblioteca, esta não dispõe de plano, mapa acessível visual, tátil para orientação aos usuários com limitação visual na entrada da edificação para reconhecimento e localização dos espaços da edificação.

Na ausência do mapa tátil, deverá ter um piso direcional, a ABNT NBR 16537 (2016) menciona piso direcional dentro da edificação como uma forma de referência para a pessoa com deficiência visual e a NBR 9050 recomenda o mapa tátil como uma das possibilidades de referência de localização dentro da edificação quando não houver piso tátil direcional. A maçaneta da porta, tipo alavanca, parcialmente de acordo com a recomendada pela norma, pois apesar da altura estar dentro dos parâmetros de 1,10 m não há uma boa empunhadura com extremidade arredondada e curvada, podendo ser acionada até mesmo com o antebraço sem a possibilidade de torcer o pulso para acioná-la, aplicando o sexto princípio do desenho universal, baixo esforço físico, necessitando ser substituída por uma compatível com a norma.

Quanto à iluminação, os espaços internos da BCCB são iluminados tanto com luz artificial, quanto com luz natural, devido a possuir estrutura em vidro em boa parte da edificação. As duas formas de iluminação concomitantes são indicadas pela norma. Isso 
também facilita a circulação das pessoas nas dependências e nas rotas acessíveis. Uma boa iluminação nos espaços internos da biblioteca é essencial para executar as atividades pertinentes a este ambiente, como atividades acadêmicas de pesquisa e leitura.

A NBR 9050 (2020) informa que apesar das pessoas com deficiência visual não identificarem as cores, elas podem perceber tons claros e escuros nos ambientes. "O contraste visual entre superfícies adjacentes facilita a percepção e a legibilidade da informação desejada pelas pessoas com deficiência visual” (ABNT 9050, 2020 p. 141). Daí a importância de observar as normas para a correta iluminação e a cor das paredes nos espaços internos de uma edificação.

Quanto ao revestimento do piso da BCCB, este é de cor opaca, contrastando com as paredes, mas deve ser evitado o polimento deste com produtos de limpeza, a fim de evitar reflexos com a iluminação local, o que dificulta a percepção de espaço pelas pessoas com baixa visão.

No piso superior, em rota acessível, encontrou-se um capacho, com altura máxima compatível à recomendada NBR 9050, que menciona quando existente não podem ser soltos, com altura não superior a $5 \mathrm{~mm}$, superfícies sem enrugamento e felpas sem comprometer o deslocamento das pessoas, sendo cumprido esse requisito no caso da BCCB.

Em relação aos desníveis, há no primeiro piso, em forma de degraus, associados às rampas, conforme prevê a norma. Um lance de dois degraus separa a área de atendimento ao usuário de parte do acervo, cabines de leitura individual, salas de estudo em grupo e o Laboratório de Acessibilidade e Inclusão (LACI).

As rampas e escadas do primeiro piso não possuem guardar-corpos ou corrimãos, o que está parcialmente coerente com a norma, pois a NBR 14718:2019 sobre Esquadrias-Guardacorpos para edificação prevê o mínimo de 1,00 m de desnível para se ter o guarda-corpo como segurança, mas o corrimão é exigido para todas as rampas, devendo ter duas alturas entre 0,70 m e 0,92 m, conforme ABNT 9050 (2020). A altura do guarda-corpo deve ser igual ou maior a $1,10 \mathrm{~m}$, o que diverge dos 0,84 m encontrados no da rampa que dá acesso ao segundo pavimento da biblioteca. Quanto à largura da rampa, o espaço livre para circulação indicado é de 1,50 m, admitido, conforme o fluxo de pessoas, o mínimo de 1,20 m. Nesse item, a largura de 1,35 m da rampa está de acordo com o intervalo determinado pela norma. 
Observou-se corredores estreitos, além de obstáculos como lixeira próxima à entrada de um dos corredores, dificultando a circulação de quem tem limitação visual. A largura livre dos corredores entre as estantes do acervo variou entre $0,90 \mathrm{~m}$ e $0,67 \mathrm{~m}$ portanto, nem todos estão de acordo com o mínimo de $0,90 \mathrm{~m}$ indicado na norma.

$\mathrm{Na} \mathrm{BCCB}$ há dois sanitários coletivos, localizados no primeiro piso, um masculino e outro feminino, contemplando boxes para pessoas com mobilidade reduzida, mas não há um com entrada independente, como indica a norma. Isto deve-se à necessidade de o usuário com deficiência poder entrar com acompanhante do sexo oposto (cônjuge, filhos, mãe, pai etc.), caso necessite de auxílio. A abertura da porta deve ser para fora, facilitando o resgate à pessoa em caso de socorro, quando for o caso desta estiver caída ao chão próximo à porta (ABNT 9050, 2020), o que não ocorre nos sanitários da BCCB, além da ausência de sinalização de sanitário destinado para pessoas com deficiência ou mobilidade reduzida.

Observou-se que alguns itens estão de acordo com a norma, mas outros necessitam de adaptações para serem utilizados com confiança e autonomia pelos usuários com limitação visual.

\subsubsection{Acessibilidade comunicacional na BCCB}

A acessibilidade comunicacional abrange a avaliação das sinalizações tátil, visual e sonora dos espaços e serviços da biblioteca, de modo a verificar se estes estão acessíveis de acordo com as normas ABNT 9050, 16537.

A sinalização é uma forma de comunicar aos usuários onde se localizar dentro do ambiente informacional, indicando para onde se dirigir ao necessitar de determinado serviço, uns às vezes explícitos, de acordo com o layout, outros nem tanto, se não estiverem indicados em placas de sinalização visual, tátil ou sonora orientando o usuário da biblioteca.

De acordo com o princípio dos dois sentidos da transmissão da informação dados pela ABNT 9050 (2020), pelo menos dois sentidos devem estar presentes: visual e tátil ou visual e sonoro, de forma autoexplicativa, legível, concisa e perceptível para todos, dependendo do tempo de permanência na instalação da sinalização, se permanente ou temporária.

Sinalização visual inclui mensagens de texto, figuras, contrastes e símbolos. Para este tipo, recomenda-se para maioria das sinalizações que haja letras maiúsculas e minúsculas, com 
fundos claro-escuro ou escuro-claro, sem serifa ou qualquer distorção na fonte tipográfica ou texto na vertical. As exceções são as mensagens de advertência, como rotas de fuga e saídas de emergência e frases curtas, devendo ser em caixa alta (ABNT 9050, 2020).

Ainda segundo a ANBT 9050 (2020), no que tange à sinalização sonora, esta é essencial para a comunicação das pessoas com deficiência visual. Permite a comunicação pela audição por meio de sinais tanto sonoros verbais digitalizados ou sintetizados. Deve contemplar as categorias informativa de forma permanente e a de emergência de forma permanente e temporária, inclui-se aí os alarmes sonoros que devem ser instalados em áreas internas e externas de confinamentos, como sanitários e boxes acessíveis, diferenciados dos alarmes de incêndio. Devem estar associados a alarmes vibratórios em sincronia com os visuais intermitentes. Na BCCB inexiste esse tipo de sinalização.

Igualmente importante é o braille para boa parte das pessoas com limitação visual, o que não dispensa as informações na forma "visual e tátil, com caracteres ou símbolos em relevo, exceto na sinalização do corrimão" (ABNT 9050, 2020, p. 38).

As sinalizações devem estar presentes na entrada da edificação com os horários de funcionamento; mapa acessível tátil, piso, através do piso tátil direcional e de alerta; degraus, corrimãos das escadas, rampas, pavimentos, elevadores, travessias, estacionamento, mobiliário, no caso das bibliotecas, em estantes e expositores de material bibliográfico, etiquetas com número de chamada na lombada dos livros, portas dos cômodos, nos sanitários ou salas, rotas de fuga, etc.

Para auxiliar a mobilidade de forma autônoma e com segurança das pessoas com deficiência visual, a sinalização do piso, conforme já mencionado, é feita através dos pisos táteis de alerta e de direção, observando a norma específica para esse tipo de sinalização, a NBR 16537:2016. Não há na referida biblioteca esse tipo de sinalização como forma de orientação espacial.

A BCCB contempla de forma parcial o princípio dos dois sentidos. A sinalização é feita em sua maioria pelo sentido visual, com placas de sinalização variando com fundo preto e letras em caixa alta na cor branca, fundo branco e letras escuras ou fundo verde e letras brancas fotoluminescentes para sinalização de emergência.

Nas portas e passagens quando sinalizadas devem conter, segundo a norma, "[...] números e/ou letras e/ou pictogramas e sinais com texto em relevo, incluindo Braille. [...]” e 
ainda, seguir alguns aspetos como: [...] ser centralizada, e não pode conter informações táteis. Para complementar a informação instalada na porta, deve existir informação tátil ou sonora na parede adjacente a ela ou no batente [...]" (ABNT 9050, 2020, p. 46).

A sinalização nas portas e passagens da BCCB não está de acordo com o recomendado pela norma, à exceção da sinalização do LACI, onde há em Braille e por meio de símbolos, por exemplo, pictogramas.

O SIA para pessoas com deficiência visual, o pictograma representado na cor preta sobre fundo branco, podendo ser disposto também na cor branca em fundo azul ou preto, indica um espaço com acessibilidade, o que não ocorre com a sinalização dos sanitários com acesso para deficientes, que devem com sinalização centralizada indicando por meio de símbolos, sanitários masculino e feminino, tal sinalização não contém informações complementares necessárias sinalizando esta informação, como as que recomenda a norma.

Na rampa que dá acesso ao segundo piso, o guarda-corpo não tem uma sinalização visual, tampouco a relação da sinalização visual relacionada ao braille ou em alto relevo. Igual ocorre com os degraus de uma das escadas, estantes e etiquetas das publicações do acervo.

Observou-se apenas a sinalização fotoluminescente nos degraus isolados do térreo, faltando adequar a sinalização na escada com acesso ao setor administrativo.

Das escadas, somente os degraus, considerados isolados (sequência com até dois degraus), os que dividem o acervo do rol de atendimento possuem uma sinalização em toda a extensão do degrau, abrangendo o piso e o espelho com uma faixa de no mínimo $3 \mathrm{~cm}$ de largura em contraste com o piso adjacente e de preferência fotoluminescente ou retroiluminado. Os demais deverão ter valores de maior ou igual a $7 \mathrm{~cm}$ de comprimento e $3 \mathrm{~cm}$ de largura, seguindo as características de contraste já citadas para degraus isolados, conforme estabelecidos na norma ABNT 9050 (2020). 


\subsubsection{Acessibilidade informacional na BCCB}

universitária

Os aspectos anteriormente abordados não deixam de ter sua parcela de importância na acessibilidade em si, mas como a principal atividade de uma biblioteca universitária é oferecer insumos informacionais, não somente fontes de informação convencionais (o livro impresso), mas as que já são acessíveis ou que precisarão ser adaptadas para sê-las, colocadas à disposição com um tratamento diferenciado, no que tange a depender de conhecimentos a mais por parte dos profissionais bibliotecários, além dos já inerentes ao seu ofício, direcionado às particularidades das pessoas com deficiência.

Por isso, a avaliação de acessibilidade informacional é essencial para saber se a informação disponível em diversos suportes e meios está acessível a todos de forma fácil, completa e objetiva, complementada pelos outros tipos de acessibilidade, garantindo não somente o acesso, mas a acessibilidade a esta informação, esteja onde estiver.

A acessibilidade informacional relaciona-se ao conteúdo do acervo, como livros, periódicos, folhetos, jornais, trabalhos acadêmicos de conclusão de curso, informações encontradas em fontes informacionais provenientes tanto do mercado editorial, quanto da literatura cinzenta, tendo a equipe da biblioteca universitária selecionando, adquirindo, catalogando, indexando, organizando e disseminando essa informação de acordo com o interesse de seus usuários no âmbito da instituição, administrados através de seus regulamentos e regimento, armazenados e registrados por meio dos diversos suportes (papel, multimeios) e formatos (impresso em Braille, ampliado, ePUB, PDF, HTML) se compatíveis com as tecnologias assistivas atuais e aos diversos dispositivos utilizados para leitura digital (computadores, tablets, dispositivos para leitura digital, celular).

O acervo impresso da BCCB está localizado em seções como, acervo geral, periódicos, seção Piauí, destinada às publicações sobre o Estado e de autores piauienses, acervo histórico, seção de referência, destinadas apenas para consulta, repositório institucional, página da biblioteca na web e no LACI.

Para atender a demanda dos usuários com deficiência visual, no LACI há materiais bibliográficos em braille, como a tabela periódica de elementos químicos, LDB, o Estatuto da Pessoa com Deficiência e literaturas brasileira e estrangeira, entre outros que são solicitados sob demanda à equipe da BCCB e adaptam o material não acessível necessário ao acompanhamento das disciplinas dos cursos dos discentes. 
As informações e o acervo disponível na página da $\mathrm{BCCB}$, na internet, estão parcialmente acessíveis. Compõem-se do acesso ao catálogo on-line, link com informações sobre a criação da BCCB; visita virtual, e-books, normas de empréstimo, produtos e serviços, Política de Aquisição de Livros, coleções, recursos humanos, espaço físico, dados estatísticos da BCCB e setoriais, ficha catalográfica-solicitação; equipe SIBI/UFPI, o Fale Conosco, normas de trabalhos acadêmicos, espaço digital de um banco privado. O link para inscrição em palestras e minicursos presente na página encontrava-se desabilitado.

\subsubsection{Acessibilidade instrumental na BCCB}

Instrumentos tecnológicos para a acessibilidade são essenciais para que as pessoas com deficiência visual possam estudar, trabalhar, praticar suas atividades como qualquer outra pessoa, a exemplo, as tecnologias assistivas são primordiais para a vida ativa das pessoas com deficiência visual.

Deve-se observar a realidade e a adaptabilidade de cada um ao instrumento que melhor se adapta. Para os estudos, há quem prefira ou mesmo tenha mais habilidades com o livro em braille, ao audiolivro, e-books, tipo PDF. Para a escrita manual, existe o reglete, punção e a régua para assinatura de pessoas com baixa visão.

No LACI, setor da BCCB de apoio à pessoa com deficiência visual, os instrumentos acessíveis disponíveis são: 6 computadores adaptados com software leitor de tela DosVox, teclados com as letras $\mathrm{F}$ e J destacadas como referência para digitação, fones de ouvido, mouses, linha braille ou display braille (utilizado por pessoa com surdocegueira); dois scanners, uma impressora braille, 5 máquinas de escrever em braile. 2 cubos mágicos, um em alto relevo e outro em braile; 3 geoplanos, 1 dominó, também em alto relevo, 2 sorobãs, uma calculadora sonora com voz sintetizada em Língua Portuguesa, um reglete e punção.

Como pode-se perceber, há bastantes instrumentos capazes de auxiliar os usuários na biblioteca para se ter acesso à informação, mesmo que esta não esteja totalmente acessível, os instrumentos cumprem o papel de adaptação às necessidades informacionais dos usuários com deficiência visual. 


\section{Considerações finais}

universitária

Um estudo como este dá uma dimensão aproximada dos inúmeros aspectos intrínsecos relacionados à acessibilidade informacional. Aspectos estes que dependem de legislações em vários âmbitos, normas, políticas públicas, conhecimento resultante de pesquisas e aplicações prévias de várias áreas do conhecimento, colocando a gestão de uma biblioteca como principal operador da engrenagem no que diz respeito ao direcionamento da acessibilidade informacional em uma biblioteca universitária, não excluindo a responsabilidade de outros agentes correlatos.

Com a pesquisa, percebeu-se uma dificuldade em encontrar conceitos sobre acessibilidade informacional na literatura. Não sendo uma temática muito explorada nesse ponto, conforme confirmado também por Fernandes (2018):

Percebeu-se que cada autor trata da temática sob uma ótica distinta, o que evidencia ainda mais a abrangência do tema. Contudo, embora ressaltem sua importância e finalidade, não foi encontrado neles nenhuma proposta de definição para o termo além do proposto por Santos e Araújo (2015) (FERNANDES, 2018, p. 42).

A acessibilidade informacional não é termo isolado, dependendo não somente da equipe de uma biblioteca universitária, mas de processos e outros tipos de acessibilidade. Processos que incluam e garantam que as pessoas com deficiência visual cheguem ao ensino superior, permaneçam e concluam seus cursos, utilizando os espaços e as fontes bibliográficas da biblioteca universitária no que lhe é direito de forma plena como qualquer usuário desta.

Entre os pontos que requerem ajustes de acordo com as normas da ABNT 9050 (2020) e ABNT 16537 (2016) na BCCB, estão a falta do piso tátil de alerta, tanto no entorno da BCCB, quanto em seu espaço interno, algumas rampas com guarda-corpo, sanitário com entrada independente, sinalização adequada em braille.

Acerca dos itens encontrados com acessibilidade, estavam o transporte público, o estacionamento com vagas reservadas para pessoas com deficiência; a existência de um laboratório equipado com instrumentos que auxiliam as pessoas com deficiência visual a acessarem a informação, que sem estes, seria mais difícil o acesso à leitura e informação, sendo assim, este um dos pontos positivos da pesquisa, entendendo-se que há uma acessibilidade instrumental presente na biblioteca.

Dessa forma, a acessibilidade informacional na BCCB dá-se de forma parcial para as pessoas com deficiência visual, necessitando adequações quanto à acessibilidade arquitetônica e comunicacional, levando em consideração o escopo deste artigo. 
O importante é que já há um caminho traçado para o atendimento das necessidades informacionais de pessoas com limitação visual na BCCB, com instrumentos tecnológicos, voltados para facilitar o acesso à leitura e à informação no espaço da biblioteca para esse público, com ajustes em planos de desenvolvimento institucional e de unidade e a implantação destes, aos poucos, as barreiras vão sendo eliminadas e sendo direcionadas para uma acessibilidade plena possível. No entanto, recomenda-se aos gestores, verificarem a atualização das normas e legislações, capacitar servidores acerca da temática, aplicando em seus diversos aspectos relacionados à oferta de produtos e serviços para as pessoas com deficiência visual no âmbito da biblioteca.

\section{Referências}

ABNT. NBR 14022: Acessibilidade em veículos de características urbanas para o transporte coletivo de passageiros. Rio de Janeiro, 2011.

ABNT. NBR 14718: esquadrias-corpos para edificação: requisitos, procedimentos e métodos de ensaio. Rio de Janeiro, 2019.

ABNT. NBR 16537: Sinalização tátil no piso: diretrizes para elaboração e projetos de instalação. Rio de Janeiro, 2016.

ABNT. NBR 9050: acessibilidade a edificações, mobiliário, espaços e equipamentos urbanos. 4. ed. Rio de Janeiro, 2020.

BARDIN, Laurence. Análise de conteúdo. Tradução de Luís Antero Reto e Augusto Pinheiro. São Paulo: Edições 70, 1977.

BRASIL. Lei 13.146 de 06 de julho de 2015. Institui a lei brasileira de inclusão da pessoa com deficiência (estatuto da pessoa com deficiência). Brasília, DF, 2015. Disponível em: http://www.planalto.gov.br/ccivil_03/_Ato2015-2018/2015/Lei/L13146.htm. Acesso em: 25 jan. 2016.

D'ABREU, João Vilhete Viegas et al. Maquete tátil da biblioteca central césar lattes da UNICAMP: uma experiência. Rev. ACB: Biblioteconomia em Santa Catarina, Florianópolis, v. 13, n. 1, p. 268-275, jan/jun. 2008. Disponível em:

https://revista.acbsc.org.br/racb/article/view/560/685. Acesso em: 07 jan. 2019.

FERNANDES, Joana D’ Arc Páscoa Bezerra. Diagnóstico da acessibilidade informacional na Biblioteconomia brasileira. 119 f. Dissertação (Mestrado em Ciência da Informação) Universidade Federal do Ceará, Fortaleza, 2018. Disponível em: http://www.repositorio.ufc.br/bitstream/riufc/33425/3/2018_dis_jdpbfernandes.pdf. Acesso em: 07 jun. 2019. 
FERREIRA, Gabriela Ayres; CIANCONI, Regina de Barros. Acessibilidade dos deficientes visuais e cegos às informações de Bibliotecas Universitárias na web. Informação \& Sociedade: Estudos, João Pessoa, v. 21, n. 2, p. 151-163, maio./ago. 2011.Disponívem em: https://periodicos.ufpb.br/ojs2/index.php/ies/article/view/10248. Acesso em: 07 jun. 2019.

GIL. Antonio Carlos. Como elaborar projetos de pesquisa. 5.ed. São Paulo: Atlas, 2010.

GIL. Antonio Carlos. Métodos e técnicas de pesquisa social. 6.ed. São Paulo: Atlas, 2011.

IBGE. Censo Demográfico 2010: releitura dos dados de pessoas com deficiência no Censo Demográfico 2010 à luz das recomendações do Grupo de Washington: nota técnica n. 1, jul. 2018.

MALHEIROS, Tania Milca de Carvalho. Produtos e serviços de informação para pessoas com deficiência visual. Orientador: Murilo Bastos da Cunha. 2019. 561f. Tese (Doutorado em ciência da informação) - Faculdade de Ciência da Informação, UNB, Brasília, 2019. Disponível em: https://repositorio.unb.br/bitstream/10482/34969/1/2019_TaniaMilcadeCarvalhoMalheiros.pd f. Acesso em: 30 set. 2020.

NICOLETTI. Tamini Farias. Checklist para bibliotecas: um instrumento de acessibilidade para todos. 2010. Trabalho de conclusão de curso (Graduação em Biblioteconomia e Comunicação) - Universidade Federal do Rio Grande do Sul, Porto Alegre, 2010. Disponível em:

https://www.lume.ufrgs.br/bitstream/handle/10183/28114/000766975.pdf?sequence=1\&isAll owed=y. Acesso em: 10 nov. 2019.

PASSOS, Jeane dos Reis; VIEIRA, Ricardo Quintão. Desenvolvendo competências em formação para deficiêntes visuais: estudo de caso. Revista ACB: Biblioteconomia em Santa Catarina, Florianópolis, v. 13, n. 1, p. 276-281, jan./jun. 2008. Disponível em: https://revista.acbsc.org.br/racb/article/view/559/684. Acesso em: 17 out. 2019.

PUPO, Daise Tallarico; CARVALHO, Silvia Helena Rodrigues de; OLIVEIRA, Vanessa Cristina. Educação inclusiva e bibliotecas acessíveis. Revista ACB: Biblioteconomia em Santa Catarina, Florianópolis, v.13, n.1, p.259-267, jan./jun., 2008. Disponível em: https://revista.acbsc.org.br/racb/article/view/562/686. Acesso em: 17 out. 2019.

RONCHETTI, Eduardo. Conheça as principais diferenças entre a NBR 9050:2015 e 2020. [ S. l.: s. n.], 2020. 1 vídeo (93 min). Disponível em: https://www.youtube.com/watch?v=jfdMjQUxXgE\&t=1370s. Acesso em: 30 out. 2020.

SANTOS, Christiane Gomes dos; ARAÚJO, Wagner Junqueira de. Acessibilidade informacional: um estudo sobre configurações de segurança em objetos digitais acessíveis segundo análise de aceitação por pessoas com deficiência visual. Pesquisa Brasileira em Ciência da Informação e Biblioteconomia, João Pessoa, v. 10, n. 2, p. 209-222, 2015. Disponível em: https://periodicos.ufpb.br/ojs/index.php/pbcib/article/view/26227/14203. Acesso em: 02 dez. 2019.

SASSAKI, Romeu Kazumi. Inclusão: acessibilidade no lazer, trabalho e educação. Revista Nacional de Reabilitação (Reação), São Paulo, Ano XII, mar./abr. 2009, p. 10-16. 
Disponível em: https://files.cercomp.ufg.br/weby/up/211/o/SASSAKI__Acessibilidade.pdf?1473203319. Acesso em: 02 dez. 2019.

SCOTT JÚNIOR, Valmôr. Acessibilidade às pessoas com deficiência na educação superior: Universidade Federal de Santa Maria - RS. In: CONGRESSO NACIONAL DE EDUCAÇÃO, 10,; SEMINÁRIO INTERNACIONAL DE REPRESENTAÇÕES SOCIAIS, SUBJETIVIDADE E EDUCAÇÃO, 1., 2011, Curitiba. Anais [...]. Curitiba: PUCPR, 2011. Disponível em: https://educere.bruc.com.br/CD2011/pdf/5737_2649.pdf. Acesso em 10 nov. 2019.

SOUZA, Osvaldo de; TABOSA, Hamilton Rodrigues. Virando a página: um novo conceito de acessibilidade na web para deficientes visuais. Informação \& Sociedade: Estudos, João Pessoa, v. 24, n. 1, p. 145-161, jan./abr. 2014. Disponível em: https://periodicos.ufpb.br/ojs2/index.php/ies/article/view/16366. Acesso em: 2 out. 2019.

TORRES, Elizabeth Fátima; MAZZONI, Alberto Angel; ALVES, João Bosco da Mota. A acessibilidade à informação no espaço digital. Ciência da Informação, Brasília, v. 31, n. 3, p. 83-91, set./dez. 2002. Disponível em: Disponível em:

http://revista.ibict.br/cienciadainformacao/index.php/ciinf/article/view/153/132. Acesso em: 20 jan. 2016.

UFPI. Biblioteca. [Teresina], 2016. Disponível em: http://www.ufpi.br/bccb. Acesso em: 15 ago. 2016.

VIGENTIM, Uilian Donizeti. Tecnologia assistiva: analisando espaços de acessibilidade às pessoas com deficiência visual em universidades públicas, 2014. 123 f. Dissertação.

(Mestrado em Educação Escolar) - Universidade Estadual Paulista "Júlio de Mesquita Filho", 2014. Disponível em:

https://repositorio.unesp.br/bitstream/handle/11449/115666/000809686.pdf?sequence=1\&isAl lowed=y. Acesso em: 25 set. 2016.

YIN, Robert K. Estudo de caso: planejamento e métodos. Tradução de Daniel Grassi. 3. ed. São Paulo: Bookman, 2005. 